\title{
Orexin-A Infusion in the Locus Ceruleus Triggers Norepinephrine (NE) Release and NE-Induced Long-Term Potentiation in the Dentate Gyrus
}

\author{
Susan G. Walling, ${ }^{1}$ David J. Nutt, ${ }^{2}$ Margaret D. Lalies, ${ }^{2}$ and Carolyn W. Harley ${ }^{1}$ \\ ${ }^{1}$ Department of Psychology, Memorial University of Newfoundland, St. John's, Newfoundland, Canada A1B 3X9, and 2Psychopharmacology Unit, School of \\ Medical Sciences, University of Bristol, BS8 1TD Bristol, United Kingdom
}

\begin{abstract}
The orexins (ORX-A/ORX-B) are neuroactive peptides known to have roles in feeding and sleep. Evidence of dense, excitatory projections of ORX-A neurons to the noradrenergic pontine nucleus, the locus ceruleus (LC), suggests ORX-A also participates in attention and memory. Activation of LC neurons by glutamate produces a $\beta$-adrenergic receptor-mediated long-term potentiation (LTP) of the perforant path-evoked potential in the dentate gyrus, a target structure of the LC that has been implicated in memory. We asked whether ORX-A also activates norepinephrine (NE)-induced LTP by initiating NE release in the hippocampus. Here, we show that ORX-A infusion $(0.25-25 \mathrm{fmol})$ into the LC produces a robust, $\beta$-adrenergic receptor-dependent, long-lasting potentiation of the perforant path-evoked dentate gyrus population spike in the anesthetized rat. Pharmacological inactivation of the LC with an $\alpha_{2}$-adrenergic receptor agonist, before ORX-A infusion, prevents this potentiation. Analysis of NE concentrations in the hippocampus after ORX-A infusion into the LC reveals a transient, but robust, increase in NE release. Thus, this study demonstrates that the dense orexinergic projection to the LC promotes the induction of NE-LTP in the dentate gyrus. ORX-A modulation of LC activity may provide important support for the cognitive processes of attention and memory.
\end{abstract}

Key words: hypocretin; noradrenaline; noradrenergic; hippocampus; perforant; learning

\section{Introduction}

Orexin (ORX) was implicated initially in feeding and sleep (de Lecea et al., 1998; Sakurai et al., 1998). However, ORX axons project widely in the brain and spinal cord (Cutler et al., 1999; Date et al., 1999; Nambu et al., 1999), suggesting ORX modulates multiple brain and behavioral systems. ORX neurons originate in the lateral hypothalamus, a region implicated in intracranial selfstimulation (Milner, 1991) and in facilitating learning and memory (Destrade and Jaffard, 1978; Huston and Mueller, 1978; Coulombe and White, 1980, 1982; Aldavert-Vera et al., 1996; Redolar-Ripoll, 2002). Recent studies support a facilitating role for ORX in tasks like those enhanced by lateral hypothalamic stimulation (Jaeger et al., 2002; Telegdy and Adamik, 2002). We propose one mechanism for ORX (and lateral hypothalamic) involvement in learning and memory is the dense orexinergic innervation of the locus ceruleus (LC) (Cutler et al., 1999; Date et al., 1999; Nambu et al., 1999), which has a high density of mRNA for the ORX-A receptor (Trivedi et al., 1998; Hervieu et al., 2001; Marcus et al., 2001).

The LC is the primary source of forebrain norepinephrine

Received Nov. 2, 2003; revised July 13, 2004; accepted July 15, 2004

This work was supported by Canadian Natural Science and Engineering Council Grant A9791 and by a Leverhulme Trust Visiting Professorship to C.W.H. We thank Dr. Richard S. Neuman for thoughtful comments on this manuscript. Correspondence should be addressed to Dr. Carolyn W. Harley, Department of Psychology, Memorial University of Newfoundland, St. John's, Newfoundland, Canada A1B 3X9. E-mail: charley@mun.ca. DOI:10.1523/JNEUROSCI.1587-04.2004

Copyright $\odot 2004$ Society for Neuroscience $\quad 0270-6474 / 04 / 247421-06 \$ 15.00 / 0$
(NE) and is known to be involved in attention and memory (Berridge and Waterhouse, 2003). ORX neurons make asymmetrical connections with tyrosine hydroxylase-positive neurons in the LC, suggesting ORX provides excitatory input to noradrenergic neurons (Horvath et al., 1999). Application of ORX in vitro or in vivo increases LC activity (Hagan et al., 1999; Horvath et al., 1999; Bourgin et al., 2000; van den Pol, 2002) and produces a tetrodotoxin-resistant depolarization, indicating ORX directly activates LC neurons (Ivanov and Aston-Jones, 2000).

One target of LC projections is the hippocampus, a structure implicated in memory. The hippocampus has only modest ORX input (Cutler et al., 1999; Nambu et al., 1999) and ORX receptor density (Trivedi et al., 1998) but significant noradrenergic innervation, particularly in the dentate gyrus (Loy et al., 1980). NE produces a long-lasting potentiation of the glutamatergic perforant path input to the dentate gyrus (Neuman and Harley, 1983). This NE-induced long-term potentiation (NE-LTP) occurs without tetanization. Glutamatergic activation of the LC induces LC firing (Harley and Sara, 1992) and produces a longlasting, $\beta$-adrenergic receptor-dependent potentiation of the dentate gyrus population spike (Harley and Milway, 1986; Harley and Evans, 1988). However, duration of potentiation in vivo with $\mathrm{NE}$ application or glutamatergic LC activation is variable, and only $\sim 50 \%$ of experiments demonstrate potentiation exceeding $30 \mathrm{~min}$. In vitro, $\beta$-adrenergic receptor-dependent NE-LTP is consistently long lasting, accompanied by increases in cAMP (Stanton and Sarvey, 1985a) and dependent on protein synthesis 
(Stanton and Sarvey, 1985b), common characteristics of memory mechanisms.

Presently, there is little evidence linking the robust ORX innervation of the LC to a physiological action of the LC in a target structure. The present study demonstrates that ORX-A infused in the LC produces robust, transient NE release in the hippocampus and consistent NE-LTP in the dentate gyrus. This long-lasting potentiation depends on $\beta$-adrenergic receptors and is sustained for hours after the transient NE elevation in the hippocampus.

\section{Materials and Methods}

\section{Electrophysiologial experiments}

Subjects and surgical procedures. Subjects were male Sprague Dawley rats, 250-400 gm (Memorial University of Newfoundland), receiving water and regular rat chow ad libitum and housed under climate-controlled conditions with a $12 \mathrm{hr}$ light/dark cycle (lights on at 8:00 A.M.). All animal procedures were reviewed by the Institutional Animal Care Committee and were in conformity with the guidelines set out by the Canadian Council on Animal Care.

Rats were anesthetized with urethane ( $1.5 \mathrm{gm} / \mathrm{kg}$, i.p.) and placed in a stereotaxic instrument in the skull flat position. Trephine holes were drilled for electrodes and cannula placement. A 22 gauge guide cannula (Plastics One, Roanoke, VA), angled $20^{\circ}$ from the vertical, was implanted $2.3-2.5 \mathrm{~mm}$ above the LC [12.5-12.6 $\mathrm{mm}$ posterior and $1.3 \mathrm{~mm}$ lateral from the midline] and secured with dental acrylic to a small jeweler's screw. A concentric bipolar stimulating electrode (NE-100; Kopf Instruments, Tujunga, CA) was directed at the perforant path $(7.2 \mathrm{~mm}$ posterior and $4.1 \mathrm{~mm}$ lateral to bregma and $\sim 3.0 \mathrm{~mm}$ ventral from brain surface). An adjustable dual recording assembly allowing independent manipulation of two glass micropipettes, one filled with saline and the other with the $\beta$-adrenergic antagonist propranolol (PROP; $100 \mathrm{~mm}$; Sigma, St. Louis, MO), was aimed at the granule cell layer of the dentate gyrus $(3.5 \mathrm{~mm}$ anteroposterior and $2.0 \mathrm{~mm}$ lateral from bregma and $\sim 2.5-2.8 \mathrm{~mm}$ from brain surface). The tips of the pipettes were separated by $\sim 500-750 \mu \mathrm{m}$.

Stimulation and recording. The perforant path was stimulated at $0.5 \mathrm{~Hz}$ (0.2 msec monophasic pulse). The evoked responses from the granule cell layer were filtered $(1 \mathrm{~Hz}$ to $3 \mathrm{kHz})$ and digitized at $10 \mathrm{kHz}$. The recording pipettes (3-5 M $\Omega$ ) were maneuvered to provide maximal positive going waveforms. Initially, an input-output current intensity series (I/O curve) was determined (50-1000 $\mu \mathrm{A}$, using $50 \mu \mathrm{A}$ increments), sampling three evoked potentials at each current level (interstimulus interval, $10 \mathrm{sec}$ ). The current intensity used for baseline measurements was the current producing $\sim 50 \%$ of the maximal population spike. Waveforms were collected using DataWave software and analyzed offline. Evoked responses were sampled every $30 \mathrm{sec}$ for a minimum of $1 \mathrm{hr}$ before drug infusion.

Pharmacology. ORX-A (California Peptide, Napa, CA) was made up in sterile saline (100 pM, $1 \mathrm{~nm}, 10 \mathrm{~nm}, 100 \mathrm{~nm}$ ) and kept frozen until used. An infusion cannula (28 gauge; Plastics One) was attached to a $0.5 \mu \mathrm{l}$ microsyringe by autoanalyzer tubing (Fisher Scientific, Pittsburgh, PA) and gently lowered into the LC. ORX-A or saline $(200-250 \mathrm{nl})$ was infused into the LC over a period of $30-60 \mathrm{sec}$, and the infusion cannula was left in place for $3 \mathrm{~min}$ after the infusion. DL-PROP (100 mM; Sigma), used in the second recording pipette, was mixed fresh in sterile saline. DL-PROP has been shown to be effective in blocking dentate gyrus noradrenergicinduced potentiation in vitro (Lacaille and Harley, 1985; Stanton and Sarvey, 1985b; Dahl and Sarvey, 1989). Of importance for the present study, DL-PROP has blocked the effects of LC activation in potentiating the dentate gyrus-evoked potential in vivo. We previously used DL-PROP (Harley and Evans, 1988) and timolol (Harley and Evans, 1988; Munro et al., 2001) in micropipettes to attenuate noradrenergic effects in the dentate gyrus, but the report that PROP, not timolol, blocks lateral perforant path potentiation in vitro (Bramham et al., 1997) led us to select PROP here. To directly block LC activation, clonidine (CLON; 3.75 mm; Sigma) was mixed in saline, and $200 \mathrm{nl}$ was infused into the LC 5 min before ORX-A (1 nM). A similar concentration of CLON has been shown previously to silence LC neurons (Berridge et al., 1993).

\section{Microdialysis experiments}

Subjects were male Wistar rats (260-300 gm) obtained from Bantin and Kingman (Hull, UK). Food and water was available ad libitum. All animal procedures were performed in accordance with the requirements of the United Kingdom Animals (Scientific Procedures) Act, 1986.

Rats were anesthetized with urethane ( $1.5 \mathrm{gm} / \mathrm{kg}$, i.p. $)$ and placed in a stereotaxic instrument in the skull flat position. Holes were drilled for placement of a microdialysis probe $(5.3 \mathrm{~mm}$ posterior and $5 \mathrm{~mm}$ lateral to bregma) directed at the hippocampus, and a 22 gauge guide cannula ( $12.4 \mathrm{~mm}$ posterior and $1.2 \mathrm{~mm}$ lateral to bregma with a $20^{\circ}$ angle from vertical) was directed at the LC. The probe was placed $6.5 \mathrm{~mm}$ below brain surface, and the guide cannula was lowered to $5.5 \mathrm{~mm}$ below brain surface. A 28 gauge infusion cannula extended an additional $1 \mathrm{~mm}$ when inserted. The guide cannula was lowered in $0.5 \mathrm{~mm}$ steps if no effect of ORX-A infusion on NE release was observed. ORX-A (a gift from Dr. M. S. Harbuz, University of Bristol, Bristol, UK) was mixed in saline and kept frozen until required.

NE diasylate in the hippocampus was obtained using a concentric dialysis probe constructed as described by Harley et al. (1996), but using a $4 \mathrm{~mm}$ exposed membrane. The larger probe provided a more stable sample of NE levels. To reach a greater area of hippocampal tissue, it was placed $1.8 \mathrm{~mm}$ more posterior than the recording site. The assumption was made that relative changes in NE release will reflect the influence of LC activity throughout the hippocampus. All subregions of the hippocampus, including the dentate gyrus, were sampled at the probe site.

The microdialysis probe was perfused continually $(1.19 \mu \mathrm{l} / \mathrm{min})$ with artificial cerebrospinal fluid (in mM: $147 \mathrm{NaCl}, 3 \mathrm{KCl}, 1.3 \mathrm{CaCl}_{2}$, and 1 $\mathrm{MgCl}_{2}$ ). Samples of $20 \mu \mathrm{l}$ were collected every $20 \mathrm{~min}$ until three consecutive baseline samples were stable. After ORX-A infusion into the LC, sampling continued until NE returned to baseline. Analysis of NE was performed by means of HPLC with electrochemical detection (Harley et al., 1996). In brief, the mobile phase was prepared using a stock mixture of $24 \mathrm{~mm}$ sodium acetate, $15 \mathrm{~mm}$ citric acid, and $2.3 \mathrm{~mm}$ octane-sulfonic acid in deionized water, to which methanol $(13 \% \mathrm{v} / \mathrm{v})$ was added. The $\mathrm{pH}$ was adjusted to 5.0 with $10 \mathrm{~mm} \mathrm{NaOH}$ before filtering and degassing. The mobile phase was then pumped through the system at a rate of $1.0 \mathrm{ml} /$ min (3 $\mu \mathrm{m}$ ODS; $12.5 \mathrm{~cm}$ length, $4.6 \mathrm{~mm}$ inner diameter; Hichrom, Theale, Berkshire, UK) while being maintained at a temperature of $32.5^{\circ} \mathrm{C}$. Electrochemical detection was performed via an Antec Leyden Intro detector with the flow cell set at a potential of $+700 \mathrm{mV}$ and output to a chart recorder. NE standards were run before each experiment.

\section{Histology and statistical analysis}

On the conclusion of all experiments, a final infusion of 200-250 nl of $1 \%$ methylene blue (electrophysiology) or polygraph ink mixed $50 \%$ with $0.25 \mathrm{~m}$ glutamate (microdialysis) was infused into the LC to mark the infusion site. Rats were decapitated, and the brains were removed quickly and frozen. Saggital sections $(30 \mu \mathrm{m})$ were taken to verify LC cannula placement.

Population spike amplitude and EPSP slope were measured as detailed in the inset to Figure 1. Briefly, the population spike amplitude was measured as the difference between the peak and valley of the downward deflecting spike (c). The EPSP slope was measured as: voltage (b-a)/time (a-b). There were no significant differences in baseline EPSP slope or population spike amplitude between the saline and PROP pipettes before commencement of the experiments.

The effects of ORX-A infusion in the LC were determined by averaging the last $15 \mathrm{~min}$ of the $3 \mathrm{hr}$ recording period after ORX infusion, and responses were compared with the average of the $60 \mathrm{~min}$ baseline period. Hippocampal NE levels measured by microdialysis were also compared with baseline data. Repeated-measures ANOVAs were used on raw data, and post hoc comparisons were made using Duncan's multiple range test $(p<0.05)$.

\section{Results \\ Histology}

Cannula placements for positive ORX-A effects were within 300 $\mu \mathrm{m}$ of the LC, consistent with the dendritic arborization of this 
A
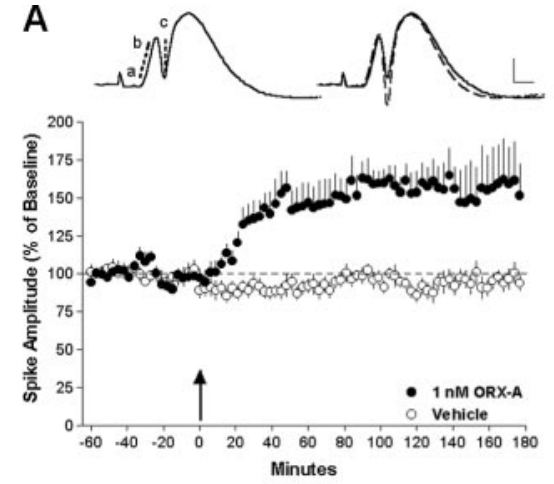

C

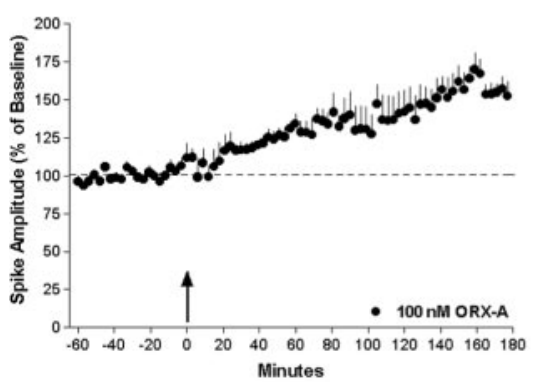

B

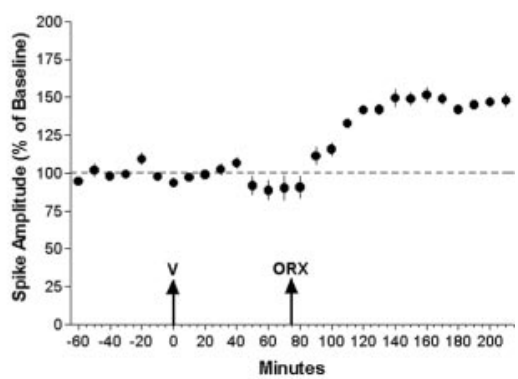

D

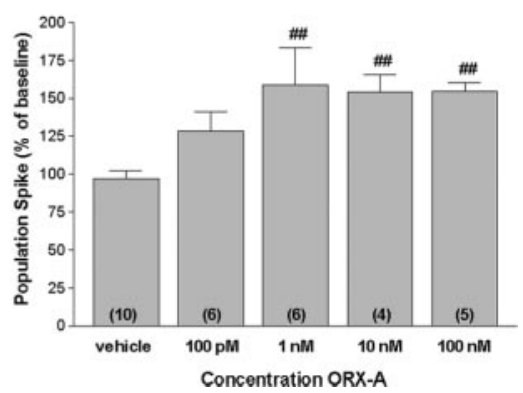

Figure 1. ORX-A infusion in the $L C$ enhanced population spike amplitude at concentrations of $1 \mathrm{~nm}$ or higher. $A$, inset, Evoked potential parameters measured were EPSP slope ( $b-a /$ time) and population spike amplitude (c). Sample waveforms from one rat at baseline (solid line) and at $180 \mathrm{~min}$ after $1 \mathrm{~nm}$ ORX-A (broken line). Calibration: $4 \mathrm{mV}, 2 \mathrm{msec}$. A, Population spike amplitude with vehicle $(n=10)$ and $1 \mathrm{~nm} O R X-A(n=6)$ infusion in the LC. $B$, An experiment with saline infusion in the $L C$, followed 75 min later by $1 \mathrm{~nm}$ ORX-A infusion. V, Vehicle. C, Population spike amplitude with $100 \mathrm{~nm}$ ORX-A infusion in the $\mathrm{LC}(n=5)$. D, Population spike amplitude for vehicle and the four concentrations of ORX-A 180 min after infusion in the LC. The data shown in $A-C$ are 3 min means \pm SEM. The data in Dillustrate 15 min averages (165-180 min after LC infusion) \pm SEM. ${ }^{\# \#} p<0.01$.

A

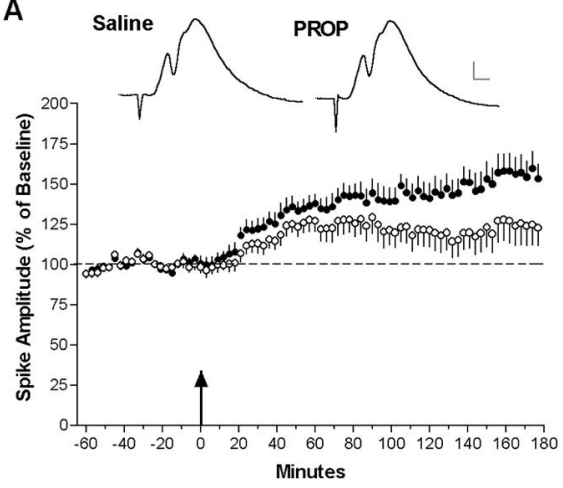

B

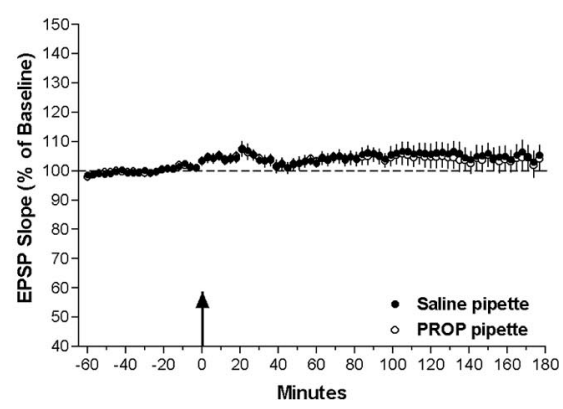

Figure 2. $\quad \beta$-Adrenergic receptor blockade in the dentate gyrus attenuated ORX-A potentiation effects. The EPSP slope was unaffected. $A$, inset, Baseline waveforms from saline and PROP pipettes for one experiment. Calibration: $4 \mathrm{mV}, 2 \mathrm{msec}$. Population spike amplitude $(A)$ and EPSP slope $(B)$ patterns summed over the three effective concentrations of ORX-A (1-100 nM) for both the saline and PROP pipettes are shown. PROP reduced the ORX-A effect on the population spike $\left(F_{(1,12)}=23.2 ; p<0.0004\right)$, implicating activation of $\beta$-adrenergic receptors in the dentate gyrus as mediators of the potentiation.

region (Aston-Jones et al., 1995). In the electrophysiological experiments, placements $(n=5)$ that were dorsoposterior to the LC by $450-700 \mu \mathrm{m}$ were negative. In the microdialysis experiments, negative ORX-A infusions were seen posterior $(500-1000 \mu \mathrm{m}$; $n=3)$, dorsal (500-1000 $\mu \mathrm{m} ; n=2)$ and ventral $(400 \mu \mathrm{m} ; n=$ 2 ) to the LC. This pattern of placement results suggests ORX-A infusions must be targeted relatively close to the nucleus to be effective.
ORX-A infusion in the LC potentiates perforant path-evoked population spike amplitude through a $\beta$-adrenergic receptor mechanism

Analysis (ANOVA; group $\times$ infusion) of the perforant path-dentate gyrus-evoked population spike $3 \mathrm{hr}$ after ORX-A infusion into the LC showed a significant interaction $\left(F_{(4,25)}=2.87 ; p<0.04\right.$; on raw data). Post hoc analysis revealed that ORX-A infusion into the LC produced an increase of the population spike amplitude at three concentrations of ORX-A $(1 \mathrm{nM}$, $p<0.002 ; 10 \mathrm{~nm}, p<0.007 ; 100 \mathrm{~nm}, p<$ 0.0004 ) (Fig. 1). Potentiation was not observed with vehicle infusions (Fig. $1 A, B, D$ ) or with 100 pm infusions (Fig. $1 D$ ). Potentiation appeared more rapidly for the $1 \mathrm{nM}$ infusion than the 10 or $100 \mathrm{~nm}$ infusions, which were similar (Fig. 1, compare $A, C$ ) (time $\times$ concentration; $F_{(1,8)}=3.03 ; p<$ 0.007; post hoc effect at $1 \mathrm{hr}$ time point).

For the three effective ORX-A concentrations, a two-way repeated-measures ANOVA (concentration $\times$ pipette) was performed to assess whether the $\beta$-adrenergic antagonist PROP or the ORX concentration affected the final level of potentiation. There was no differential effect of concentration on the final potentiation (mean potentiation at $3 \mathrm{hr}, 155 \%$ ). However, at the PROP pipette potentiation was significantly reduced $\left(F_{(1,12)}=23.19 ; p<\right.$ 0.0004 ; mean final potentiation, $124 \%$ ) (Fig. 2A). There was no long-term effect of ORX-A on EPSP slope at any concentration (Fig. 2B). ORX-A infusion did commonly elicit a modest, transient increase in EPSP slope at infusion that returned to baseline levels.

To address the specificity of LC activation, we infused CLON, an $\alpha_{2}$-adrenceptor agonist, into the LC to inhibit firing 5 min before an infusion of $1 \mathrm{nM}$ ORX-A (Fig. 3). Infusion of CLON before ORX-A prevented the facilitation of the population spike (CLON plus 1 nM ORX-A, 103\%; final increase with $1 \mathrm{~nm}$ ORX-A, $156 \%)$, confirming the critical role of LC activation in producing the potentiation observed with ORX-A.

\section{ORX-A infusion in the LC transiently enhances NE release in the hippocampus}

Although application of the ORXs onto LC neurons by either bath application (Hagan et al., 1999; van den Pol et al., 2002) or by infusion into the LC in vivo (Bourgin et al., 2000; Kiyashchenko et al., 2001) can increase the firing rate of LC neurons, the enduring change in response to the perforant path stimulus led us to ask whether ORX-A infused into the $\mathrm{LC}$ was also producing an enduring change in NE levels in the hippocampus. To assess this, we sampled NE levels in the hippocampus using microdialysis 


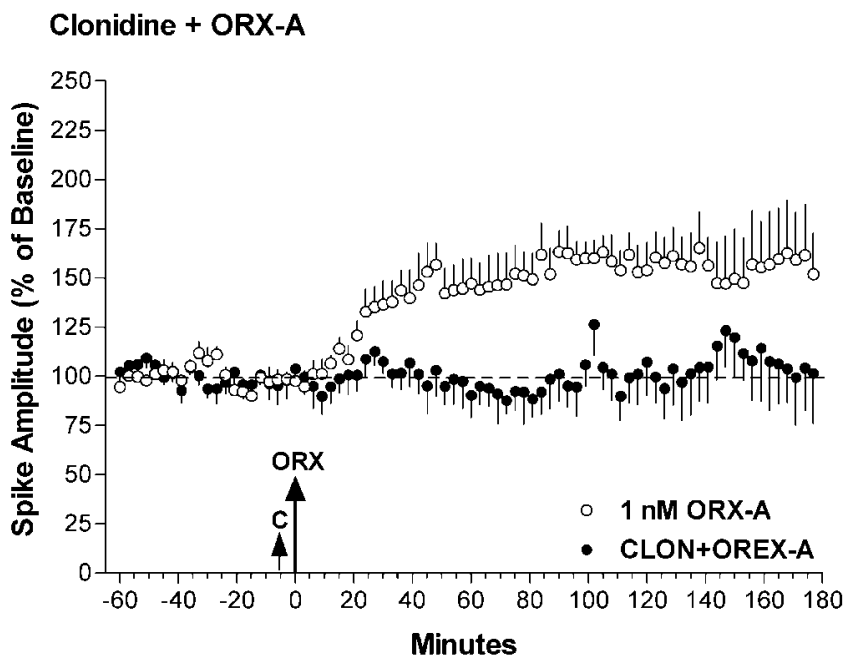

Figure 3. Previous infusion of the $\alpha_{2}$-receptor agonist CLON in the LC prevents potentiation induced by ORX-A infusion in the LC. Population spike amplitude for rats receiving either $1 \mathrm{~nm}$ ORX-A $(n=6)$ or CLON, followed by 1 nм ORX-A $(n=5)$. CLON prevented the long-term population spike potentiation observed previously in animals receiving $1 \mathrm{~nm}$ ORX-A. The data are shown as 3 min means \pm SEM. C, CLON.

before and after effective ORX-A (100 nM, $10 \mathrm{nM}, 1 \mathrm{nM})$ infusion into the LC. A repeated-measures ANOVA (concentration $\times$ sample) was performed on the three baseline levels of hippocampal NE to assess differences between groups (100 nM, $10 \mathrm{nM}, 1 \mathrm{nM}$ ) and across samples $(-3.0$ to -1.0$)$. No differences were found in basal levels of NE among the groups or among the three successive baseline NE responses, and, as expected, no interactions between concentrations and baseline samples were found. The mean NE baselines across the three groups of ORX-A (100 nM, 10 $\mathrm{nM}, 1 \mathrm{nM})$ concentrations were $13.30,13.88$, and $13.24 \mathrm{fmol} / 20$ $\mu l$, respectively.

A second repeated-measures ANOVA (concentration $\times$ sample) was performed comparing the mean of the baseline samples to the three samples after ORX-A infusion into the LC (samples $1.0-3.0)$. There were no differential effects because of the concentration of ORX-A infused, but there was a significant effect of sample $\left(F_{(3,30)}=16.55 ; p<0.0001\right)$. Post hoc comparisons revealed that the first NE sample for the 20 min after the infusion of ORX-A into the LC was significantly increased above baseline for each of the three concentrations of ORX-A (Fig. 4A-C). The mean increase in the first sample averaged over the three effective concentrations of ORX-A was $188 \%$ of baseline. Samples of NE in the hippocampus taken in the subsequent 20 min periods did not differ from baseline NE levels for any concentration of ORX-A, indicating a transient release of NE after ORX-A activation of the LC.

To compare ORX-A with glutamate effects on NE release, and to probe site effectiveness, glutamate infusions were performed at the conclusion of 10 experiments. In each case, glutamate increased NE release. In seven experiments, microdialysis measurements were continued for an additional hour to evaluate time course; again, a transient NE release was seen in the first $20 \mathrm{~min}$ sample $(p<0.007)$ (Fig. $4 D)$. The mean percentage increase was similar to that seen with ORX-A activation.

A second infusion of ORX-A at the same site was often unsuccessful in eliciting a second increase in NE (6 of 11 tries). Mechanical infusion effects (vehicle or vehicle plus peptide) were evaluated by comparison to a later glutamate infusion at the same site. These comparisons revealed that NE release was triggered by mechanical stimulation on 2 of 10 occasions (Fig. $4 E$ ).

\section{Discussion}

This is the first physiological study to examine the modulatory effects of ORX-A on the neural mechanisms of attention and memory processes by way of orexinergic activation of LC neurons. ORX-A application to LC neurons initiated robust, but transient, NE release in the hippocampus and produced a large and long-lasting, $\beta$-adrenergic receptor-dependent potentiation of the dentate gyrus population spike in anesthetized rat. ORX-A neurons terminating in the LC provide a pathway for orexinergic modulation of attention and memory processes in the intact rat by regulating noradrenergic input to target areas of the LC. The sensitivity of this system is such that $<1 \mathrm{fmol}$ of ORX is sufficient to evoke NE release and facilitate the population spike. The potent effects on the perforant path-evoked potential suggest the ORX-LC pathway could play a significant role in the neural plasticity that underlies learning and memory and provides a mechanism for hypothalamic modulation of cognition. These results may have clinical relevance, as in narcolepsy, in which there is an ORX deficit, memory impairments (Henry et al., 1993), and difficulties with vigilance and attention tasks (Rogers and Rosenberg, 1990; Rieger et al., 2003).

The long-lasting facilitation of perforant path throughput to the rest of the trisynaptic hippocampal circuit resulting from ORX-A infusion into the LC resembles that observed after the infusion of glutamate infusion into the LC. Both are dependent on activation of $\beta$-adrenergic receptors (Harley and Milway, 1986; Harley and Evans, 1988). However, details of the facilitation vary; ORX-A infusion into the LC produces a substantial ( $\sim 155 \%$ of baseline), and consistently enduring, NE-LTP in contrast to the more variable effects seen with glutamate infusion. The overall pattern of potentiation also varies somewhat with an earlier and more abrupt potentiation after glutamate infusion and a more gradual increase over time after ORX-A infusion.

Differences between the effects of ORX-A and glutamate on the firing pattern of LC neurons may explain the variability of their action on the perforant path population spike. The infusion of glutamate into the LC results in a $\sim 500 \mathrm{msec}$ burst of spikes recorded from LC neurons, followed by a silent period and then a gradual return to baseline firing (Harley and Sara, 1992). In contrast, ORX-A infusion results in a tonic activation of LC neurons (Kiyashchenko et al., 2001), through a slower G-protein-coupled receptor mechanism. When $200 \mathrm{~nm}$ ORX-A is infused in the vicinity of the LC, muscle tone modulation parallels, with a delayed onset, the transient, dose-dependent rise in LC firing (Kiyashchenko et al., 2001). Doses in the present study were lower than those evaluated for changes in muscle tone. It is likely in the present study that LC neurons were activated tonically, but transiently, by the infusion of ORX-A. ORX also increases synchronous firing of LC neurons (van den Pol et al., 2002). A combination of tonic firing with enhanced synchrony may be relevant to the robust, consistent NE-LTP induced by ORX infusion in the LC. Aston-Jones et al. (1999) have also proposed a unique role for synchronous LC activity in focused attention.

A new study in our laboratory has shown that glutamatergic activation of the LC in awake rats produces a delayed $\beta$-adrenergic receptor-dependent facilitation of both the EPSP slope and population spike amplitude $24 \mathrm{hr}$ after the LC glutamate infusion, an effect that does not require short-term facilitation (Walling and Harley, 2004). Whether orexinergic activation of LC neurons can initiate a similar pattern of synaptic strength changes at $24 \mathrm{hr}$ remains to be examined.

In the study by Walling and Harley (2004) with intracerebro- 
A

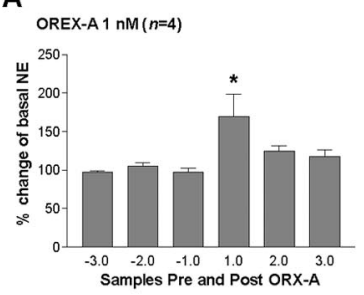

D

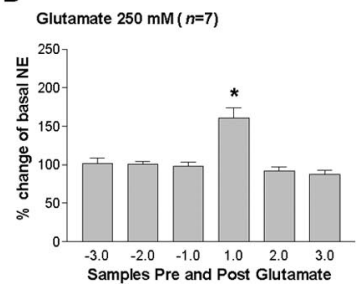

B

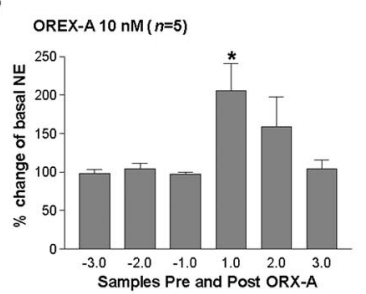

E

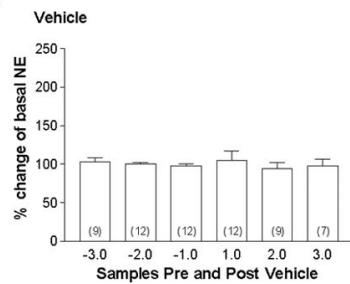

C

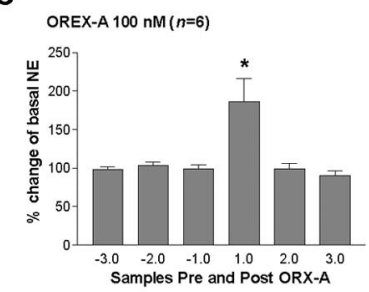

pus. The long-lasting increase in the population spike $(>3 \mathrm{hr})$ in the face of only a transient increase in evoked NE release supports the hypothesis that elevated NE is an initiating event for the enhancement of spike amplitude and that elevated NE is not required for maintenance of that enhancement. The greater effectiveness of ORX-A, relative to glutamate, in promoting consistently enduring NE-LTP may relate to the duration or pattern of LC cell firing induced by ORX-A.

ORX-A appears to recruit and reinforce forebrain noradrenergic activation in several ways. In addition to the ability of ORX-A to directly initiate NE release by activating the LC, ORX-A promotes NE release presynaptically when applied to cerebrocortical slices (Hirota et al., 2001). Other studies have shown intravenous infusions of ORX-A also increase glutamate release in the LC, suggesting indirect as well as direct excitatory actions of ORX-A on LC neurons (Kodama and Kimura, 2002). Thus, multiple mechanisms are in ventricular administration of $\mathrm{PROP}$, and in previous in vitro and in vivo studies with bath-applied (Stanton and Sarvey, 1985b; Dahl and Sarvey, 1989; Chaulk and Harley, 1998) or systemically administered (Harley and Milway, 1989) PROP, NE- or LCmediated potentiation in the dentate gyrus has been completely blocked. Local diffusion of a $\beta$-adrenergic receptor antagonist from a micropipette, however, attenuates, rather than completely blocks, NE effects (Munro et al., 2001). Micropipette drug diffusion in the dentate gyrus has been estimated at $<500 \mu \mathrm{m}$ (Steward et al., 1990). Some contribution is likely made to the field potential from sites that are less effectively antagonized accounting for the attenuation profile. Nonetheless, the micropipette approach addresses two issues more effectively than other methods: it controls for any changes attributable to preparation variability and it provides evidence that $\beta$-adrenergic receptors solely within the dentate gyrus participate in the LC-induced potentiation.

The low doses of ORX-A used in the present study, relative to previous in vitro and in vivo studies, may account for the lack of evidence for a dose-response relationship. In a previous in vivo study (Kiyashchenko et al., 2001), LC infusion of 200 nм produced longer latency and shorter-duration effects than infusion of $1 \mathrm{~mm}$ ORX-A (a 5000-fold difference in concentration); in the present study, $100 \mathrm{~nm}$ was the highest dose used, and the difference between the lowest and highest effective doses examined was 100 -fold. These low doses, while illustrating the high degree of LC sensitivity to ORX-A, may also have made site variability more of an issue for dose-response differences. The 100 pM dose was ineffective, but, if anything, responses were more robust with 1 nM infusions than with higher concentrations. Consistent with the lack of a dose-response in the electrophysiological experiments was the lack of a dose-response in the microdialysis studies. All of the effective ORX-A doses promoted NE release to a similar extent. The ineffectiveness of repeated doses at the same site corroborates observations of ORX-A desensitization in vitro (van den Pol et al., 2002).

Results from the microdialysis experiments demonstrate that both glutamate and ORX-A activation of LC neurons produce a transient, but robust, increase in the level of NE in the hippocam-

place to reinforce the ability of ORX-A to modulate behavior through increases in forebrain NE.

In summary, the present data confirm, in vivo, that ORX-A is a robust activator of LC neurons and can initiate NE release in an LC target structure. This ORX-A action promotes an enduring potentiation in the response of dentate gyrus neurons to their perforant path-mediated input. Electrophysiological and behavioral studies in awake rats are needed to elaborate this initial characterization of the effects of ORX-A on attention and memory mechanisms and on the modulation of NE release.

\section{References}

Aldavert-Vera L, Segura-Torres P, Costa-Miserachs D, Morgado-Bernal I (1996) Shuttle-box memory facilitation by posttraining intracranial selfstimulation: differential effects in rats with high and low basic conditioning levels. Behav Neurosci 110:346-352.

Aston-Jones G, Shipley MT, Grzanna R (1995) The locus coeruleus, A5 and A7 noradrenergic cell groups. In: The rat nervous system (Paxinos G, ed), pp 183-213. San Diego: Academic.

Aston-Jones G, Rajkowski J, Cohen J (1999) Role of locus coeruleus in attention and behavioral flexibility. Biol Psychiatry 46:1309-1320.

Berridge CW, Waterhouse BD (2003) The locus coeruleus-noradrenergic system: modulation of behavioral state and state-dependent cognitive processes. Brain Res Rev 42:33-84.

Berridge CW, Page ME, Valentino RJ, Foote SL (1993) Effects of locus coeruleus inactivation on electroencephalographic activity in neocortex and hippocampus. Neuroscience 55:381-393.

Bourgin P, Huitron-Resendiz S, Spier AD, Fabre V, Morte B, Criado JR, Sutcliffe JG, Henriksen SJ, de Lecea L (2000) Hypocretin-1 modulates rapid eye movement sleep through activation of locus coeruleus neurons. J Neurosci 20:7760-7765.

Bramham CR, Bacher-Svendsen K, Sarvey JM (1997) LTP in the lateral perforant path is $\beta$-adrenergic receptor-dependent. NeuroReport 8:719-724.

Chaulk PC, Harley CW (1998) Intracerebroventricular norepinephrine potentiation of the perforant path-evoked potential in dentate gyrus of anesthetized and awake rats: a role for both $\alpha$ - and $\beta$-adrenoceptor activation. Brain Res 787:59-70.

Coulombe D, White N (1980) The effect of post-training lateral hypothalamic self-stimulation on aversive and appetitive classical conditioning. Physiol Behav 25:267-272.

Coulombe D, White N (1982) The effect of post-training hypothalamic selfstimulation on sensory preconditioning in rats. Can J Psychol 36:57-66. 
Cutler DJ, Morris R, Sheridhar V, Wattam TAK, Holmes S, Patel S, Arch JRS, Wilson S, Buckingham RE, Evans ML, Leslie RA, Williams G (1999) Differential distribution of orexin-A and orexin-B immunoreactivity in the rat brain and spinal cord. Peptides 20:1455-1470.

Dahl D, Sarvey JM (1989) Norepinephrine induces pathway-specific longlasting potentiation and depression in the hippocampal dentate gyrus. Proc Natl Acad Sci USA 86:4776-4780.

Date Y, Ueta Y, Yamashita H, Yamaguchi H, Matsukura S, Kangawa K, Sakurai T, Yanagisawa M, Nakazato M (1999) Orexins, orexigenic hypothalamic peptides, interact with autonomic, neuroendocrine and neuroregulatory systems. Proc Natl Acad Sci USA 96:748-753.

de Lecea L, Kilduff TS, Peyron C, Gao XB, Foye PE, Danielson PE, Fukuhara C, Battenberg ELF, Gautvik VT, Bartlett FS, Frankel WN, van den Pol AN, Bloom FE, Gautvik KM, Sutcliffe JG (1998) The hypocretins: hypothalamus-specific peptides with neuroexcitatory activity. Proc Natl Acad Sci USA 95:322-327.

Destrade C, Jaffard R (1978) Post-trial hippocampal and lateral hypothalamic electrical stimulation. Facilitation on long-term memory of appetitive and avoidance learning tasks. Behav Biol 22:354-374.

Hagan JJ, Leslie RA, Patel S, Evans ML, Wattam TA, Holmes S, Benham CD, Taylor SG, Routledge C, Hemmati P, Munton RP, Ashmeade TE, Shah AS, Hatcher JP, Hatcher PD, Jones DNC, Smith MI, Piper DC, Hunter AJ, Porter RA, Upton N (1999) Orexin A activates locus coeruleus cell firing and increases arousal in the rat. Proc Natl Acad Sci USA 96:10911-10916.

Harley CW, Evans S (1988) Locus coeruleus-induced enhancement of the perforant path-evoked potential: effects of intradentate $\beta$-blockers. In: Cellular mechanisms of conditioning and behavioral plasticity (Woody CD, Alkon DL, McGaugh JL, eds), pp 415-423. New York: Plenum.

Harley CW, Milway JS (1986) Glutamate ejection in the locus coeruleus enhances the perforant path-evoked population spike in the dentate gyrus. Exp Brain Res 63:143-150.

Harley CW, Sara SJ (1992) Locus coeruleus bursts induced by glutamate trigger delayed perforant path spike amplitude potentiation in the dentate gyrus. Exp Brain Res 89:581-587.

Harley CW, Lalies MD, Nutt DJ (1996) Estimating the synaptic concentration of norepinephrine in dentate gyrus which produces $\beta$-receptor mediated long-lasting potentiation in vivo using microdialysis and intracerebroventricular norepinephrine. Brain Res 710:293-298.

Henry GK, Satz P, Heilbronner RL (1993) Evidence of a perceptualencoding deficit in narcolepsy? Sleep 16:123-127.

Hervieu GJ, Cluderay JE, Harrison DC, Roberts JC, Leslie RA (2001) Gene expression and protein distribution of the orexin-1 receptor in the rat brain and spinal cord. Neuroscience 103:777-797.

Hirota K, Kushikata T, Kudo M, Kudo T, Lambert DG, Matsuki A (2001) Orexin $\mathrm{A}$ and $\mathrm{B}$ evoke noradrenaline release from rat cerebrocortical slices. Br J Pharmacol 134:1461-1466.

Horvath TL, Peyron C, Diano S, Ivanov A, Aston-Jones G, Kilduff TS, van den Pol AN (1999) Hypocretin (orexin) activation and synaptic innervation of the locus coeruleus noradrenergic system. J Comp Neurol 415:145-159.

Huston JP, Mueller CC (1978) Enhanced passive avoidance learning and appetitive T-maze learning with post-trial rewarding hypothalamic stimulation. Brain Res Bull 3:265-270.

Ivanov A, Aston-Jones G (2000) Hypocretin/orexin depolarizes and decreases potassium conductance in locus coeruleus neurons. NeuroReport 11:1755-1758.

Jaeger LB, Farr SA, Banks WA, Morley JE (2002) Effects of orexin-A on memory processing. Peptides 23:1683-1688.

Kiyashchenko LI, Mileykovskiy BY, Lai YY, Siegel JM (2001) Increased and decreased muscle tone with orexin (hypocretin) microinjections in the locus coeruleus and pontine inhibitory area. I Neurophysiol 85:2008-2016.

Kodama T, Kimura M (2002) Arousal effects of orexin-A correlate with GLU release from the locus coeruleus in rats. Peptides 23:1673-1681.

Lacaille JC, Harley CW (1985) The action of norepinephrine in the dentate gyrus: $\beta$-mediated facilitation of evoked potentials in vitro. Brain Res 358:210-220

Loy R, Koziell DA, Lindsey JD, Moore RY (1980) Noradrenergic innervation of the adult rat hippocampal formation. J Comp Neurol 189:699-710

Marcus JN, Aschkenasi CJ, Lee CE, Chemelli RM, Saper CB, Yanagisawa M, Elmquist JK (2001) Differential expression of orexin receptors 1 and 2 in the rat brain. J Comp Neurol 435:6-25.

Milner PM (1991) Brain-stimulation reward: a review. Can J Psychol 45:1-36.

Munro CA, Walling SG, Evans JH, Harley CW (2001) $\beta$-Adrenergic blockade in the dentate gyrus in vivo prevents high frequency-induced longterm potentiation of EPSP slope, but not long-term potentiation of population spike amplitude. Hippocampus 11:322-328.

Nambu T, Sakurai T, Mizukami K, Hosoya Y, Yanagisawa M, Goto K (1999) Distribution of orexin neurons in the adult rat brain. Brain Res 827:243-260.

Neuman RS, Harley CW (1983) Long-lasting potentiation of the dentate gyrus population spike by norepinephrine. Brain Res 273:162-165.

Redolar-Ripoll D, Aldavert-Vera L, Soriano-Mas C, Segura-Torres P, Morgado-Bernal I (2002) Intracranial self-stimulation facilitates memory consolidation, but not retrieval: its effects are more effective than increased training. Behav Brain Res 129:65-75.

Rieger M, Mayer G, Gauggel S (2003) Attention deficits in patients with narcolepsy. Sleep 26:36-43.

Rogers AE, Rosenberg RS (1990) Tests of memory in narcoleptics. Sleep $13: 42-52$.

Sakurai T, Amemiya A, Ishii M, Matsuzaki I, Chemelli RM, Tanaka H, Williams SC, Richardson JA, Kozlowski GP, Wilson S, Arch JRS, Buckingham RE, Haynes AC, Carr SA, Annan RS, McNulty DE, Liu WS, Terrett JA, Elshourbagy NA, Bergsma DJ, Yanagisawa M (1998) Orexins and orexin receptors: a family of hypothalamic neuropeptides and $G$ proteincoupled receptors that regulate feeding behavior. Cell 92:573-585.

Stanton PK, Sarvey JM (1985a) The effect of high-frequency electrical stimulation and norepinephrine on cyclic AMP levels in normal versus norepinephrine-depleted rat hippocampal slices. Brain Res 358:343-348.

Stanton PK, Sarvey JM (1985b) Blockade of norepinephrine-induced longlasting potentiation in the hippocampal dentate gyrus by an inhibitor of protein synthesis. Brain Res 361:276-283.

Steward O, Tomasulo R, Levy WB (1990) Blockade of inhibition in a pathway with dual excitatory and inhibitory action unmasks a capability for LTP that is otherwise not expressed. Brain Res 516:292-300.

Telegdy G, Adamik A (2002) The action of orexin A on passive avoidance learning. Involvement of transmitters. Regul Pept 104:105-110.

Trivedi P, Yu H, MacNeil DJ, Van der Ploeg LHT, Guan XM (1998) Distribution of orexin receptor mRNA in the rat brain. FEBS Lett 438:71-75.

van den Pol AN, Ghosh PK, Liu RJ, Li Y, Aghajanian GK, Gao XB (2002) Hypocretin (orexin) enhances neuron activity and cell synchrony in developing mouse GFP-expressing locus coeruleus. J Physiol (Lond) 541:169-185

Walling SG, Harley CW (2004) Locus ceruleus activation initiates delayed synaptic potentiation of perforant path input to the dentate gyrus in awake rats: a novel $\beta$-adrenergic- and protein synthesis-dependent mammalian plasticity mechanism. J Neurosci 24:598-604. 